\title{
PEMBERITAAN BANGKITNYA PKI \\ DALAM MEDIA MASSA \\ (Analisis Semiotika Sosial M.A.K Halliday pada Isu Pemberitaan Bangkitnya Partai Komunis Indonesia di Media Online)
}

\author{
Ade Tuti Turistiati \\ Manajemen Komunikasi \\ Fakultas Ilmu Sosial dan Manajemen Institut STIAMI \\ Email : adetuti30@yahooo.com.au
}

\begin{abstract}
Mass media coverage on the rise of the Communist Party of Indonesia (PKI) became public attention including its news on online media. Online media that reported it among others are Republika.co.id, Liputan6.com, and Merdeka.com. The purpose of this study is to find out how online media in Indonesia discourse news text in the issue of the rise of PKI by using a qualitative approach, social semiotics method version of M.A.K Halliday. As an online medium that has certain characteristics such as speed, it was clearly seen in this news. The media became biased and ignored journalistic principles, including the principle of online journalism. The three online media that became the object of this study showed images and illustrations which were provocative and not in accordance to the reported facts. The three media have done news construction subjectively and were less professional.
\end{abstract}

Keywords: Online Media Online, Social Semiotics of M.A.K Halliday, Constructivism

\begin{abstract}
Abstrak
Pemberitaan media massa tentang kebangkitan Partai Komunis Indonesia (PKI) menjadi perhatian publik termasuk pemberitaannya pada media online. Media online yang memberitakan di antaranya adalah Republika.co.id, Liputan6.com, dan Merdeka.com. Tujuan penelitian ini adalah untuk mengetahui bagaimana media online di Indonesia mewacanakan teks berita dalam isu bangkitnya PKI dengan menggunakan pendekatan kualitatif, metode semiotika sosial versi M.A.K Halliday. Sebagai media online yang memiliki karakteristik tertentu seperti kecepatan, maka jelas terlihat pada pemberitaan ini. Media menjadi bias dan mengabaikan prinsip-prinsip jurnalistik, termasuk prinsip jurnalistik online. Ketiga media online yang menjadi obyek penelitian ini menampilkan gambar dan ilustrasi yang provokatif dan tidak sesuai dengan fakta yang diberitakan. Ketiga media sudah melakukan konstruksi pemberitaan secara subjektif dan kurang profesional.
\end{abstract}

Kunci: Media Online, Semiotika Sosial M.A.K Halliday, konstruksivisme

\section{PENDAHULUAN}

Dewasa ini pemberitaan tentang kebangkitan Partai Komunis Indonesia
(PKI) semakin gencar. Berbagai media massa seperti televisi, media cetak, termasuk media on line berlomba-lomba mengangkatnya ke permukaan. 
Meningkatnya kerjasama Indonesia dengan Cina di berbagai bidang dan banyaknya sumber daya manusia asal Cina yang bekerja di Indonesia pun dianggap sebagai salah satu indikasi kebangkitan PKI. Hal ini disebabkan Cina dikenal sebagai negara berideologi komunis. Cerita-cerita dan ilustrasi tentang kebiadaban PKI pada masa lalu yang telah membunuh ribuan orang menghiasi pemberitaan media massa dan mengundang pro-kontra, opini, serta diskusi tak berkesudahan.

Nara sumber utama yang sering dijadikan referensi pemberitaan tentang bangkitnya PKI ini adalah mantan Kepala Staf Kostrad Mayor Jenderal (Purn) Kivlan Zen. Media elektronik terutama media online dengan cepat dan gencar memberitakan apapun yang dikatakannya terkait PKI.

Pada bulan Mei dan Juni 2016 media massa di Indonesia ramai mewartakan tentang kebangkitan PKI. Media elektronik terutama media online dan beberapa stasiun televisi memberitakan tentang kasus tersebut. Pemberitaan beberapa media online tentang kebangkitan PKI memicu reaksi beberapa kalangan yang menganggap media terlalu membesar-besarkan ucapan atau pendapat Kivlan tanpa melakukan proses verifikasi dalam melaporkan pemberitaannya.

Kaum konstruksionis meyakini bahwa berita tidaklah mungkin merupakan cermin dan refleksi dari realitas. Hal ini disebabkan karena dalam prosesnya berita yang terbentuk merupakan konstruksi dari realitas. Lebih lanjut kaum konstruksionis memandang berita seperti sebuah drama. Ia bukan menggambarkan realitas, tetapi potret dari arena pertarungan antara berbagai pihak yang berkaitan dengan peristiwa (Eriyanto, 2007: 25). Seperti sebuah drama, ada pihak yang didefinisikan sebagai pahlawan (hero), tetapi ada juga pihak yang didefinisikan musuh dan pecundang.

Melalui penelitian ini, peneliti ingin mengetahui bagaimana media online di Indonesia mewacanakan teks berita dalam kasus pemberitaan bangkitnya PKI di Indonesia dengan menggunakan pendekatan kualitatif, metode semiotika sosial.

Peneliti menggunakan analisis semiotika sosial karena semiotika ini khusus menelaah sistem tanda yang dihasilkan oleh manusia berupa lambang dan kalimat. Adapun rumusan masalah dalam penelitian ini adalah: Bagaimana media online di Indonesia mengkonstruksi makna isu bangkitnya PKI dalam pemberitaannya?

\section{TINJAUAN TEORI/KONSEP}

\section{Media Massa}

Media Massa atau yang sering disingkat "media" saja adalah medium, alat yang atau saluran yang dipergunakan dalam proses komunikasi massa, yakni komunikasi yang diarahkan kepada orang banyak. Media massa adalah alat atau media penyampai pesan dari proses komunikasi massa dan merupakan saluran komunikasi yang memproduksi dan mendistribusikan berita, konten hiburan, visual art, dan produk budaya lainnya untuk sejumlah besar orang. 
Media massa dapat diklasifikasikan dalam tiga kelompok besar berdasarkan sifat fisik-nya:

- Media Cetak seperti, Surat Kabar, Majalah, buku

- Media Elektronik seperti, Radio, Televisi, Film, video dan audio record

- Media online sebagai media baru (Vera, 2016: 6-7).

Media baru adalah bentuk baru media yang berbasis komputer yang mana teknologi komunikasi menjadi bagian penting dalam munculnya media baru. Ragam media baru adalah internet, pesan singkat (sms), DVD, televisi kabel, Smartphone, dan lainlain.

Pesan dalam media massa dapat berupa informasi atau berita dan hiburan yang dikemas sesuai dengan bentuk medianya. Dalam paper ini penulis hanya membahas mengenai berita sebagai sebuah karya jurnalistik.

\section{Pengertian Berita}

Berita (news) merupakan informasi yang layak disajikan kepada publik. Berita yang tergolong layak adalah informasi yang sifatnya faktual, aktual, akurat, objektif, penting, dan tentu saja menarik perhatian publik. Biasanya, berita berupa pernyataan yang dipublikasikan melalui media massa (Suryawati, 2011:78).

Intinya, berita adalah laporan yang berisikan informasi yang terbaru/aktual (baru telah terjadi, bisa sementara terjadi atau akan terjadi), bersifat penting dan menarik perhatian untuk diketahui oleh publik yang mencerminkan hasil kerja jurnalistik wartawan (bukan opini atau pendapat wartawan).

\section{Objektivitas Berita}

Menurut Eriyanto (2002:132133), objektivitas dalam proses produksi berita secara umum digambarkan sebagai tidak mencampuradukkan antara fakta dengan opini. Ada banyak kriteria yang disodorkan untuk mengamati objektivitas media massa. Dengan kelebihan dan kekurangan yang melekat, satu di antaranya adalah apa yang pernah disampaikan Westerstahl (1983) yang dikutip dari buku Dennis McQuails, McQuails's Mass Communication Theory (2000). Lihat Gambar 1.

\section{Konstruksi Realitas}

Isi media pada hakikatnya adalah hasil konstruksi realitas dengan bahasa sebagai perangkat dasarnya. Sedangkan bahasa bukan saja sebagai alat merepresentasikan realitas, namun juga bisa menentukan relief seperti apa yang akan diciptakan oleh bahasa tentang realitas tersebut. Akibatnya, media massa mempunyai peluang yang sangat besar untuk memengaruhi makna dan gambaran yang dihasilkan dari realitas yang dikonstrusikannya.

Menurut Eriyanto dalam bukunya Analisis Framing, "Bagi Berger, realitas itu tidak dibentuk secara alamiah, tidak juga sesuatu yang diturunkan oleh Tuhan, tetapi sebaliknya, ia dibentuk dan dikonstruksi. Dengan pemahaman semacam ini, realitas berwajah ganda atau plural". (Eriyanto, 2002:14-15). 
Gambar 1. Bagan Westerstahl tentang Objektivitas

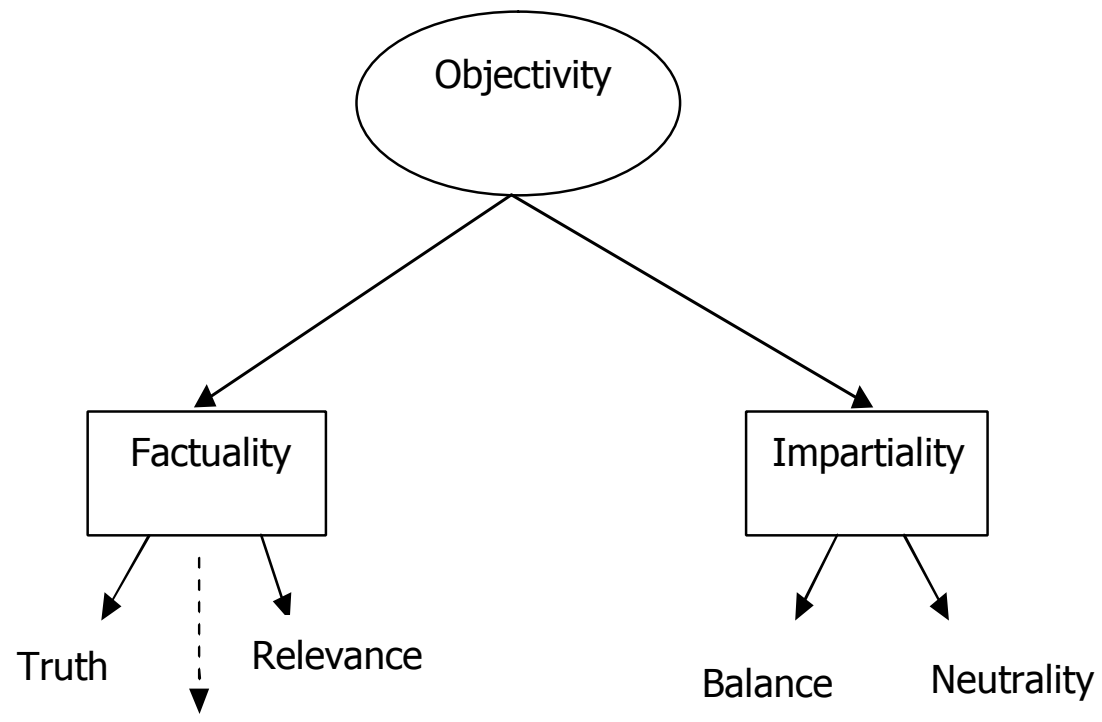

Ibnu Hamad dalam bukunya "Konstruksi Realitas Politik dalam Media Massa" mengatakan bahwa setiap upaya "menceritakan" (konseptualisasi) sebuah peristiwa, keadaan, atau benda adalah usaha mengkonstruksi realitas. Sifat dan fakta dari pekerjaan media massa adalah menceritakan peristiwa, maka kesibukan utama media massa adalah mengkonstruksikan berbagai realitas yang akan disiarkan. (Ibnu Hamad, 2004:11)

\section{Semiotika Sosial}

Semiotika sosial yakni semiotika yang khusus menelaah lambang, baik lambang berwujud kata maupun lambang berwujud bukan kata dalam satuan yang disebut kalimat. Dengan kata lain, semiotika sosial menelaah sistem tanda yang terdapat dalam bahasa.

MAK. Halliday dan Ruqaiyya Hassan yang dikutip oleh Ibnu Hamad
(2007:15), pengembang Semiotika Sosial, melihat bahwa teks memuat tiga komponen penting, yaitu:

1. Medan Wacana (field of discourse): menunjuk pada hal yang terjadi: Apa yang dijadikan wacana media massa mengenai sesuatu yang sedang terjadi di lapangan.

2. Pelibat Wacana (tenor of discourse): menunjuk pada orang-orang yang dicantumkan dalam teks (berita); sifat orang-orang itu, kedudukan dan peranan mereka. Dalam sebuah laporan (berita) ada orang dengan posisi atau jabatannya masingmasing dikutip. Mengapa orangorang itu menjadi narasumber; yang lainnya tidak. Mengapa sebuah koran dalam peristiwa itu banyak mengutip satu pihak; kurang di pihak lain? Benarkah atas alasan teknis belaka? Apalagi jika menyangkut satu pihak ditonjolkan yang baik-baiknya saja, sedangkan kalau menyangkut pihak 
Ade Tuti Turistiati, Pemberitaan Bangkitnya PKI Dalam Media Massa....

lainnya diketengahkan pendapat yang miring-miringnya saja.

3. Sarana Wacana (mode of discourse): menunjuk pada bagian yang diperankan oleh bahasa: bagaimana komunikator (baca, media massa) menggunakan gaya bahasa untuk menggambarkan medan (situasi) dan pelibat (orang-orang yang dikutip); Apakah menggunakan bahasa yang diperhalus atau hiperbolik, eufimistik atau vulgar.

Tabel 1. Unsur Semiotika M.A.K Halliday

\begin{tabular}{ll}
\hline \multicolumn{1}{c}{ Unsur } & \multicolumn{1}{c}{ Keterangan } \\
\hline $\begin{array}{l}\text { Medan Wacana } \\
\text { (field of discourse) }\end{array}$ & $\begin{array}{l}\text { Menunjuk pada hal yang terjadi: apa yang dijadikan } \\
\text { wacana oleh pelaku (media massa) mengenai sesuatu yang } \\
\text { sedang terjadi di lapangan peristiwa } \\
\text { Menunjuk pada orang-orang yang dicantumkan dalam teks } \\
\text { Pelibat Wacana }\end{array}$ \\
(foto berita): sifat orang-orang itu, kedudukan dan peranan \\
mereka. Dengan kata lain siapa saja yang dikutip dan \\
bagaimana sumber itu digambarkan sifatnya \\
Menunjuk pada bagian yang diperankan oleh bahasa: \\
bagaimana komunikator (media massa) menggunakan gaya \\
bahasa untuk menggambarkan medan (situasi) dan pelibat \\
(mode of discourse) \\
(orang yang dikutip) misalnya apakah menggunakan \\
bahasa yang vulgar, diperhalus, atau eufemistik
\end{tabular}

(Sumber: Alex Sobur, 2009: 148)

\section{METODE PENELITIAN}

Pendekatan yang digunakan dalam penelitian ini adalah pendekatan kualitatif. Bogdan dan Taylor dalam buku Lexy J. Moleong berjudul Metode Penelitian Kualitatif mendefinisikan metodologi penelitian kualitatif sebagai prosedur penelitian yang menghasilkan data deskriptif berupa kata-kata tertulis atau lisan dari orang-orang dan perilaku yang dapat diamati. Menurut mereka, pendekatan ini diarahkan pada latar dan individu tersebut secara holistik (utuh) (2007:11).

Peneliti memperoleh data-data dari berita yang disebarkan berbagai media online. Peneliti juga menggunakan pendekatan kualitatif ini karena berdasarkan data dari berita yang diperoleh akan diperoleh hasil penelitian yang bersifat deskriptif berupa kata dari objek penelitian. Selain itu dapat diperoleh hasil penelitian yang menjelaskan maksud dari peristiwa yang ada diberita tersebut.

Untuk menganalisis berita dari masing-masing media online dalam penelitian ini, metode yang digunakan adalah analisis semiotika sosial dengan menggunakan model M.A.K Halliday. Halliday telah membangun suatu kerangka kerja yang memungkinan 
untuk interaksi antara teks dan situasi (konteks) yang didasarkan pada tiga konsep yaitu medan wacana (field of discourse), pelibat wacan (tenor of discourse), dan mode wacana (mode of discours) (Sudibyo, 2001:129).

Penelitian ini dilakukan untuk mengetahui bagaimana media massa online ini mengonstruksi realitas pada suatu peristiwa menjadi sebuah berita. Penelitian ini mengenai pemberitaan bangkitnya PKI di Indonesia.

Data primer dalam penelitian ini diambil dari subjek penelitian yaitu dokumentasi berita media online sebagai berikut: Republika.co.id, Liputan6.com, Merdeka.com. Data sekunder merupakan studi kepustakaan dengan mencari berbagai referensi yang terdiri dari buku-buku, jurnal ilmiah, dan artikel internet yang mendukung penelitian ini. Teknik analisis yang digunakan adalah teknik analisis kualitatif dengan menggunakan metode semiotika sosial yang mengacu pada kerangka kerja semiotika sosial M.A.K Halliday.

\section{ANALISIS/PEMBAHASAN}

\section{Instrument Analisis Semiotika Sosial I}

Berita/Kasus Kivlan Zen: Jangan Sampai PKI Bisa Balas Dendam Kembali

Nama Media : Republika.co.id

Hari, Tanggal $\quad$ : Senin, 23 Mei 2016, 13:50 WIB

\begin{tabular}{|c|c|c|}
\hline $\begin{array}{c}\text { Aspek } \\
\text { Semiotika Sosial }\end{array}$ & Bukti Dalam Teks & Makna \\
\hline $\begin{array}{l}\text { 1. Medan } \\
\text { Wacana }\end{array}$ & $\begin{array}{l}\text {...ada pihak-pihak yang mau } \\
\text { membangkitkan komunis. Sebab, } \\
\text { kondisi Indonesia saat ini tidak } \\
\text { stabil."(p1) } \\
\text { "Pondok-pondok sekarang sudah } \\
\text { lemas, komunis sudah menyusup } \\
\text { ke mana-mana." (p3) }\end{array}$ & $\begin{array}{l}\text { Kata-kata "ada pihak-pihak..” } \\
\text { tidak jelas mengacu pada pihak } \\
\text { mana. Kesannya menunjukkan } \\
\text { banyak atau lebih dari satu } \\
\text { pihak yang mau } \\
\text { membangkitkan komunis. } \\
\text { Alasan kondisi Indonesia tidak } \\
\text { stabil digunakan sebagai satu- } \\
\text { satunya alasan untuk } \\
\text { menguatkan bangkitnya } \\
\text { komunis. } \\
\text { Pondok-pondok yang lemas } \\
\text { menunjukkan ketidakpastian. } \\
\text { Pondok apa yang dimaksud, } \\
\text { dimana, dan apa nama } \\
\text { pondoknya tidak jelas. Kata } \\
\text { "sudah lemas" tidak jelas }\end{array}$ \\
\hline
\end{tabular}


Ade Tuti Turistiati, Pemberitaan Bangkitnya PKI Dalam Media Massa....

\begin{tabular}{|c|c|c|}
\hline $\begin{array}{c}\text { Aspek } \\
\text { Semiotika Sosial }\end{array}$ & Bukti Dalam Teks & Makna \\
\hline $\begin{array}{l}\text { 2. Pelibat } \\
\text { Wacana dan } \\
\text { Kutipannya }\end{array}$ & $\begin{array}{l}\text { 1. Mantan Kepala Staf Konstrad } \\
\text { Mayor Jenderal (Purn) Kivlan } \\
\text { Zen } \\
\text { Indonesia mau maju, komunis } \\
\text { mau menikam lagi. Sifat mereka } \\
\text { memang seperti itu," katanya. } \\
\text { (p.2) }\end{array}$ & $\begin{array}{l}\text { maksudnya apa, indikasi lemas } \\
\text { juga tidak dijelaskan. } \\
\text { Kivlan menjadi satu-satunya } \\
\text { nara sumber yang menjadi } \\
\text { referensi bahwa PKI akan } \\
\text { bangkit dan melakukan balas } \\
\text { dendam. } \\
\text { Wartawan banyak mengutip } \\
\text { pernyataan Kivlan yang samar, } \\
\text { ambigu, dan multitafsir. } \\
\text { Alasan-alasan yang dia } \\
\text { kemukakan samar dan seperti } \\
\text { omong kosong belaka. } \\
\text { Pewarta tidak melakukan } \\
\text { verifikasi sama sekali dengan } \\
\text { nara sumber lainnya, baik nara } \\
\text { sumber yang mendukung atau } \\
\text { tidak mendukung } \\
\text { pernyataannya. }\end{array}$ \\
\hline 3. Moda Wacana & $\begin{array}{l}\text {...’PKI di Indonesia sebenarnya } \\
\text { masih ingin balas dendam. } \\
\text { Apalagi mereka melihat Cina } \\
\text { yang berideologi komunis } \\
\text { semakin maju. "Cina memang } \\
\text { punya ideologi komunis. Namun, } \\
\text { ekonominya kapitalisme, } \\
\text { sedangkan politiknya diktator } \\
\text { sentralistik...(p.4) }\end{array}$ & $\begin{array}{l}\text { Gambar dalam pemberitaan ini } \\
\text { provokatif seolah-olah kondisi } \\
\text { penangkapan PKI pada masa } \\
\text { lalu akan membangkitkan balas } \\
\text { dendam sekarang. } \\
\text { Cina yang komunis dihubung- } \\
\text { hubungkan dengan kebangkitan } \\
\text { PKI di Indonesia padahal } \\
\text { komunis dengan PKI itu tidak } \\
\text { sama. PKI pasti komunis tapi } \\
\text { tidak semua komunis adalah } \\
\text { PKI. }\end{array}$ \\
\hline & $\begin{array}{l}\text { Ia berharap agar umat Islam, baik } \\
\text { dari NU, Muhammadiyah, dan }\end{array}$ & \\
\hline
\end{tabular}




\begin{tabular}{|c|c|}
\hline $\begin{array}{c}\text { Aspek } \\
\text { Semiotika Sosial }\end{array}$ & Bukti Dalam Teks \\
\hline & $\begin{array}{l}\text { gereja bersatu bergabung menjadi } \\
\text { satu menghadapi PKI. Apalagi, } \\
\text { saat ini pekerja yang berasal dari } \\
\text { tentara Cina ada di mana-mana. } \\
\text { Pekerja dari Cina sudah banyak } \\
\text { bekerja di pabrik-pabrik di } \\
\text { Indonesia. (p.5) }\end{array}$ \\
\hline $\begin{array}{l}\text { 4. Interpretasi } \\
\text { dan Implikasi }\end{array}$ & $\begin{array}{l}\text { Pemberitaan seperti ini dapat menggiring opini pembaca bahwa } \\
\text { PKI benar-benar akan atau sudah bangkit. Hal ini akan } \\
\text { menimbulkan perasaan ketakutan pada masyarakat dan saling } \\
\text { mencurigai yang berujung pada perpecahan. } \\
\text { - Menghubung-hubungkan Cina dengan kebangkitan PKI akan } \\
\text { menimbulkan persepsi negatif dalam hubungan sosial, ekonomi, } \\
\text { budaya, dan keamanan dengan orang Cina yang ada di } \\
\text { Indonesia. }\end{array}$ \\
\hline
\end{tabular}

Instrument Analisis Semiotika Sosial II

Berita/Kasus : PKI Menggeliat Lagi?

Nama Media : Liputan6.com

Hari, Tanggal : 3 Juni 2016, 00:16 WIB

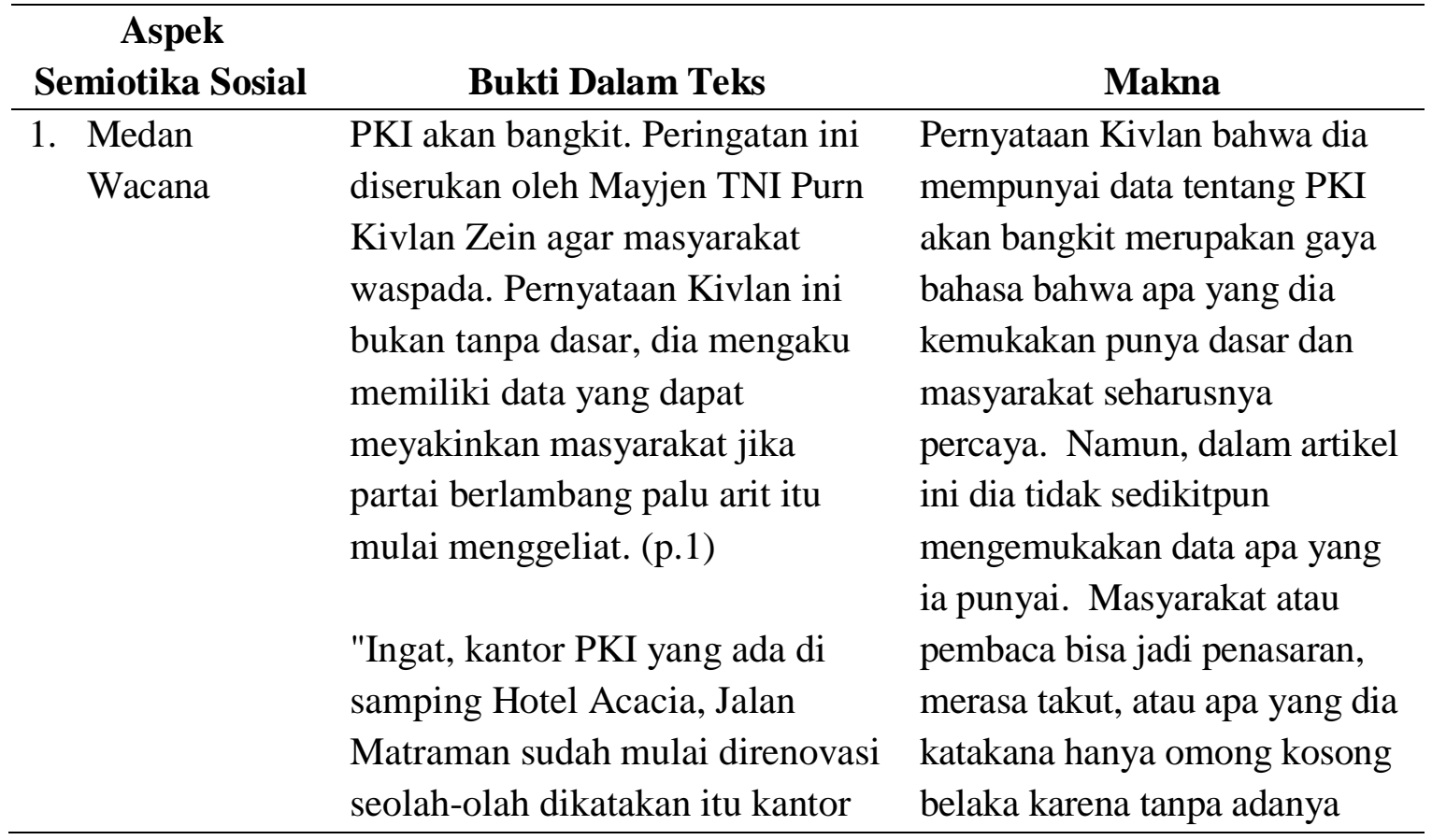


Ade Tuti Turistiati, Pemberitaan Bangkitnya PKI Dalam Media Massa....

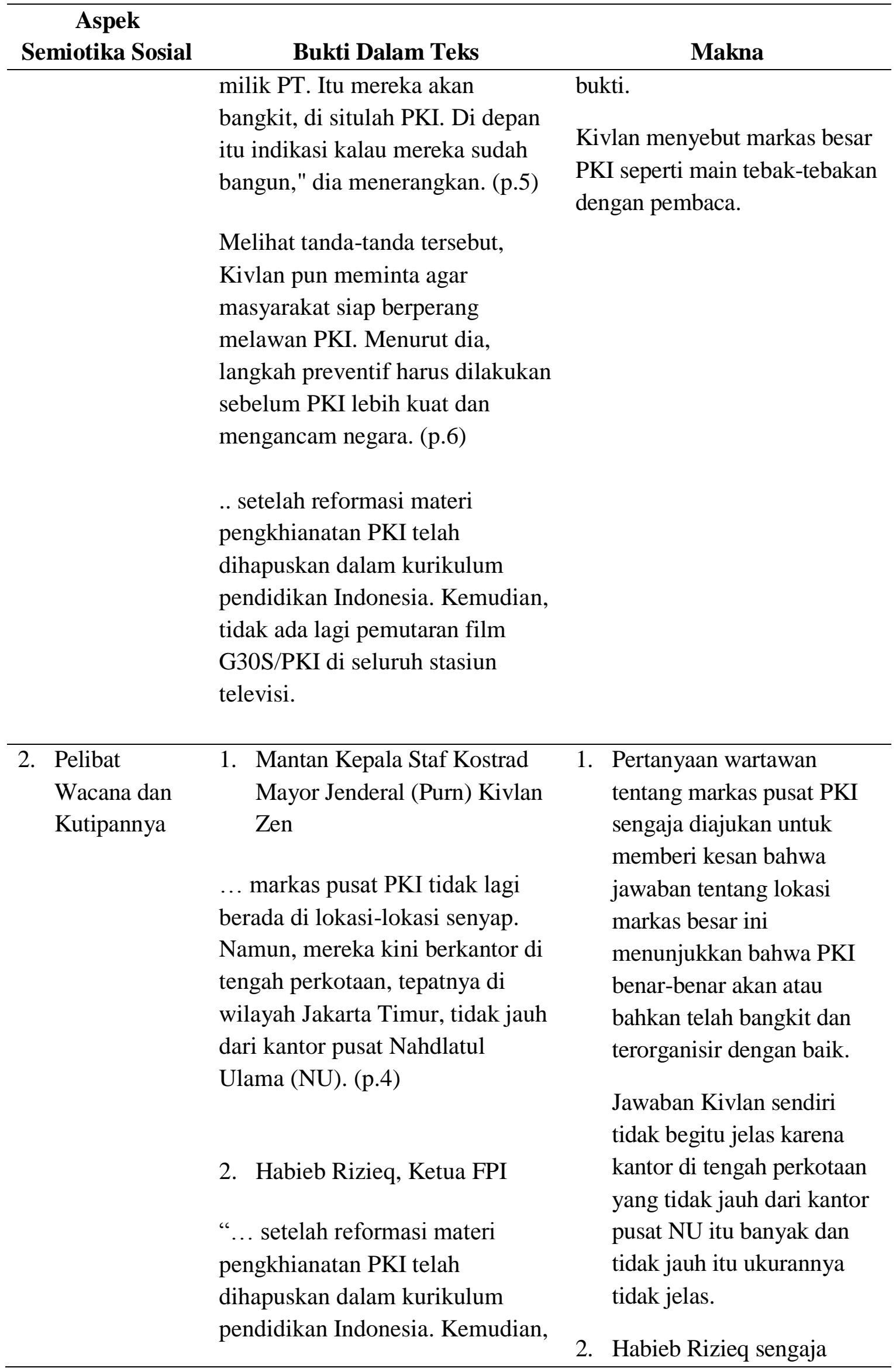




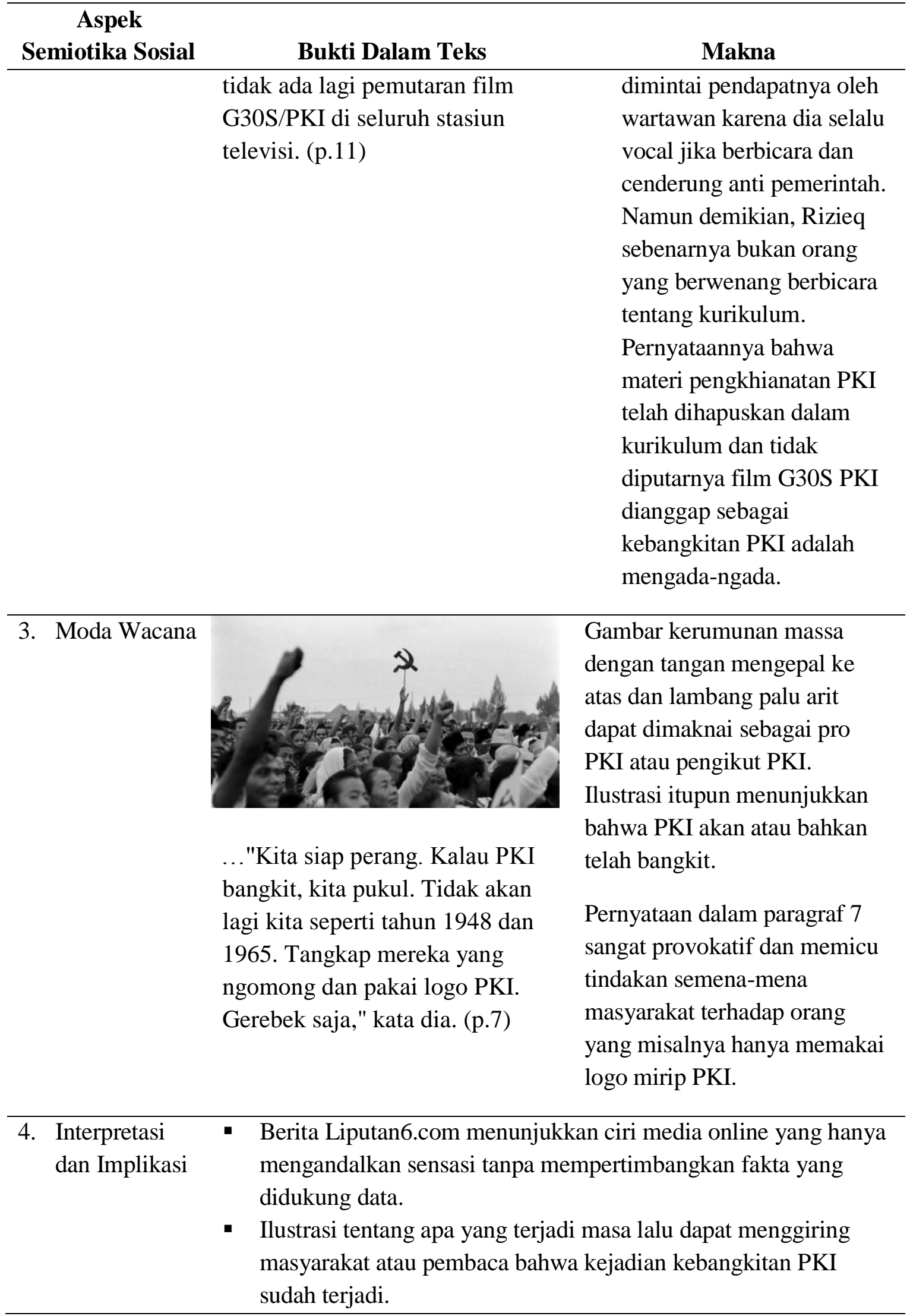


Ade Tuti Turistiati, Pemberitaan Bangkitnya PKI Dalam Media Massa....

$\begin{array}{lll}\text { Berita/Kasus } & : & \text { 'Ayo Jokowi selamatkan NKRI dari rongrongan PKI' } \\ \text { Nama Media } & : & \text { Merdeka.com } \\ \text { Hari, Tanggal } & : & \text { Jumat, } 3 \text { Juni } 201614: 58 \text { WIB }\end{array}$

\begin{tabular}{|c|c|c|}
\hline $\begin{array}{c}\text { Aspek } \\
\text { Semiotika Sosial }\end{array}$ & Bukti Dalam Teks & Makna \\
\hline $\begin{array}{l}\text { 1. Medan } \\
\text { Wacana }\end{array}$ & $\begin{array}{l}\text { Ribuan massa dari organisasi } \\
\text { Islam dan organisasi kebangsaan } \\
\text { melakukan unjuk rasa di depan } \\
\text { Istana Negara. Mereka menolak } \\
\text { Partai Komunis Indonesia (PKI) } \\
\text { tumbuh subur di Indonesia. (p.1) }\end{array}$ & $\begin{array}{l}\text { Pernyataan bahwa Partai } \\
\text { Komunis Indonesia (PKI) } \\
\text { tumbuh subur dapat dimaknai } \\
\text { sebagai bangkitnya PKI. } \\
\text { Penulisan "ribuan masa" seolah } \\
\text { ingin memberikan kesan pada } \\
\text { pembaca bahwa jumlah } \\
\text { pengunjuk rasa demikian } \\
\text { banyak dan mereka pastinya } \\
\text { yakin PKI tumbuh subur di } \\
\text { Indonesia. }\end{array}$ \\
\hline $\begin{array}{l}\text { 2. Pelibat } \\
\text { Wacana dan } \\
\text { Kutipannya }\end{array}$ & $\begin{array}{l}\text { 1. Sulaiman Nakil, anggota } \\
\text { Pergerakan Pemuda Islam. } \\
\text { "Ayo... ayo Jokowi selamatkan } \\
\text { NKRI dari rongrongan PKI" }\end{array}$ & $\begin{array}{l}\text { Wartawan tidak menjelaskan } \\
\text { Pergerakan Pemuda Islam itu } \\
\text { dari mana dan sebesar apa } \\
\text { organisasinya. Namun, teriakan } \\
\text { yang dikutipnya menimbulkan } \\
\text { kesan bahwa NKRI dalam } \\
\text { keadaan bahaya karena adanya } \\
\text { rongrongan dari PKI. }\end{array}$ \\
\hline 3. Moda Wacana & $\begin{array}{l}\text { Ribuan massa dari organisasi } \\
\text { Islam dan organisasi kebangsaan } \\
\text { melakukan unjuk rasa di depan } \\
\text { Istana Negara. Mereka menolak } \\
\text { Partai Komunis Indonesia (PKI) } \\
\text { tumbuh subur di Indonesia. (p.1) }\end{array}$ & $\begin{array}{l}\text { Ilustrasi yang ditampilkan } \\
\text { dalam berita tersebut nampak } \\
\text { tidak sesuai dengan pengunjuk } \\
\text { rasa yang ditulis berjumlah } \\
\text { ribuan. } \\
\text { Wartawan seolah } \\
\text { menyembunyikan jumlah } \\
\text { kerumunan masa tersebut dan } \\
\text { berusaha mengekskalasi } \\
\text { jumlahnya. }\end{array}$ \\
\hline 4. Interpretasi & Berita Merdeka.com menunjukka & ciri media online yang hanya \\
\hline
\end{tabular}




\begin{tabular}{clc}
\hline $\begin{array}{c}\text { Aspek } \\
\text { Semiotika Sosial }\end{array}$ & \multicolumn{1}{c}{ Bukti Dalam Teks } & Makna \\
\hline dan Implikasi & $\begin{array}{l}\text { mengandalkan sensasi dan kecepatan tanpa mempertimbangkan } \\
\text { keakurataan data. }\end{array}$ \\
\hline
\end{tabular}

Berdasarkan pembahasan di atas dapat dipahami bahwa setiap media memiliki konstruksi yang berbeda dalam setiap memberitakan suatu peristiwa. Hal tersebut karena setiap media memiliki tujuan yang berbeda, tergantung dari visi dan misi media tersebut dan maksud yang ingin disampaikan kepada masyarakat melalui pemberitaan itu. Kaum konstruksionis berkeyakinan bahwa berita tidaklah mungkin merupakan cermin dan refleksi dari realitas. Hal ini disebabkan karena dalam prosesnya berita yang terbentuk merupakan konstruksi dari realitas.

Dengan menggunakan analisis semiotika sosial model M.A.K Halliday dan Hasan yang memiliki tiga elemen yaitu medan wacana, pelibat wacana, dan moda wacana untuk menganalisis berita diperoleh hasil bahwa wacana dominan yang muncul dari berita-berita tersebut adalah kebangkitan PKI di Indonesia. Menurut peneliti ketiga media sudah melakukan konstruksi secara subjektif dan provokatif.

\section{KESIMPULAN}

Berdasarkan analisis dari teks berita yang tentang isu kebangkitan PKI yang dipublikasikan di situs berita Republika.co.id, Liputan6.com, dan Merdeka.com peneliti menarik kesimpulan sebagai berikut:

$\begin{array}{lr}\text { 1. Republika.co.id } & \text { melakukan } \\ \text { konstruksi berita } & \text { dengan }\end{array}$ menggunakan kata "kebangkitan" PKI dan gambar yang disajikan tidak sesuai dengan kejadian.

2. Liputan6.com melakukan konstruksi berita dengan pilihan kata yang ambigu, belum jelas, dan multitafsir.

3. Merdeka.com melakukan konstruksi berita yang data-datanya diduga keras tidak akurat dan cenderung membesar-besarkan fakta yang sebenarnya.

Secara keseluruhan kesimpulan yang ada yaitu, media online di Indonesia kurang cermat, lemah dalam hal verifikasi, dan subjektif dalam menyampaikan informasi mengenai isu kebangkitan Partai Komunis Indonesia (PKI), mengejar sensasi, dan mengabaikan prinsip kehati-hatiaan yang menjadi tujuan utama jurnalisme.

\section{DAFTAR PUSTAKA}

Eriyanto. 2002. Analisis Framing, Konstruksi, Ideologi, dan Politik Media. Yogyakarta: LKiS.

Halliday. M.A.K. dan Ruqaiya Hasan. 1994. Bahasa, Konteks, dan Teks, Aspek-Aspek bahasan dalam Pandangan Semiotik Sosial. Yogyakarta: Gadjahmada University Press.

Hamad, Ibnu, 2007. Analisis Wacana (Discourse Analysis) Sebuah Pengenalan Awal Jakarta, Diktat Perkuliahamn Metode Penelitian 
Ade Tuti Turistiati, Pemberitaan Bangkitnya PKI Dalam Media Massa....

Komunikasi Kulaitatif, PPS UI Jakarta, hlm.15.

Hamad, Ibnu. 2004. Konstruksi Realitas Politik dan Media Massa. Jakarta: Granit.

McQuail, Denis. 2000. McQuail's Mass Communication Theory, 4th Edition, London: Sage Publication,
Moleong, J. Lexy. 2004. Metodologi Penelitian Kualitatif. Bandung: PT Remaja Rosdakarya.

Sobur, Alex. 2009. Analisis Teks Media "Suatu Pengantar untuk Analisis Wacana, Analisis Semiotik, dan Analisis Framing. Bandung: PT. Remaja Rosdakarya.

Sudibyo, Agus. 2001. Politik Media dan Pertarungan Wacana. Yogyakarta: LKiS 